\title{
PLATÃo E A MATEMÁTICA
}

\author{
IRINEU BICUDO* \\ Instituto de Geociências e Ciências Exatas \\ da Universidade Estadual de Rio Claro
}

\begin{abstract}
RESUMO: Zenão, segundo Aristóteles, teria inventado a dialética. Essa era uma técnica retórica que sugeria, aos interlocutores em um debate, aceitassem, sem a preocupação de verificá-las verdadeiras, certas hipóteses para o início da argumentação. Dessa prática, teriam os matemáticos herdado a idéia de axiomatização. O projeto de axiomatização da matemática, levado a efeito na Academia, foi, mais provavelmente, influenciado pela dialética platônica, em sua direção ascendente, a partir das hipóteses das ciências, em busca do Princípio Não Hipotético, seu "axioma universal".
\end{abstract}

PALAVRAS-CHAVE: axiomatização; dialética; matemática.

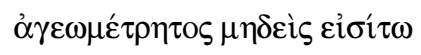

\section{Introdução}

Parece, sem qualquer sombra de dúvida, que tanto a matemática egípcia quanto a babilônia - esta, sabemos hoje, graças ao trabalho de Otto Neugebauer, bem mais refinada do que aquela - tinham a experiência como critério de verdade. Não se encontra nelas qualquer idéia que se possa ligar a uma demonstração.

Os gregos herdaram, assim nos diz a tradição, o conhecimento matemático desses povos. Mas, o que satisfazia egípcios e babilônios não bastava para agradar a exigência grega. Com os matemáticos da Grécia, a razão suplanta a empeiría como critério de verdade, tornando-se a matemática uma ciência dedutiva.

Como acontece com inúmeros fenômenos culturais, as causas dessa transformação, por que passou a matemática, perderam-se nas dobras de um passado 
remoto. Cada tentativa de reencontrá-las se tece de conjecturas mais ou menos consubstanciadas nos testemunhos, quase sempre duvidosos, de épocas bem menos recuadas. No caso que nos interessa, o historiador assemelha-se a um equilibrista que andasse em fio de aço preso entre dois distantes edifícios, a uma altura estonteante, sem ter por baixo a rede protetora que lhe amorteça a possível queda. No entanto, pulsam o coração e a audácia humana: é preciso ousar!

Assim o veremos, Szabó arrisca-se a explicar a referida mudança na matemática, dando por motivo o impacto, nessa ciência, da filosofia eleática, ou, mais precisamente, da dialética de Zenão. Hajamos por bem aceitar tal explicação.

Ora, se a dialética de Zenão, uma técnica retórica, pode dar conta do princípio da axiomatização da matemática grega, não nos parece bastante para firmar essa axiomatização como um programa a ser levado a efeito. Para tanto, foram necessárias a influência de Platão e a extensão que ele faz da dialética

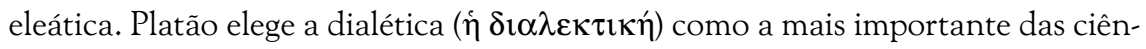
cias, a única "não hipotética". Enquanto as ciências, em particular a matemática, têm "hipóteses" como pontos de partida, e vão dessas, em movimento descendente, à dedução de suas conseqüências, a dialética, tendo pronta tal estrutura das ciências (especialmente da matemática, que é uma propedéutica a ela) parte, em

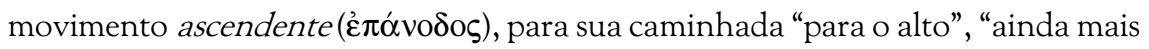
alto" (Rep. VI 511a; Féd. 101-d-e), até alcançar, se possível, o fundamento incondicional e perfeitamente seguro a que se aspira. Tal escalada fica facilitada, se feita a partir de uma axiomatização das ciências. É isso, afigura-se-nos, que fixa a axiomatização da matemática como um projeto da Academia e que redunda no caráter básico dessa ciência. Essa, a nossa tese!

\section{Platão, matemático?}

Quem pretenda falar sobre "Platão e a Matemática" haverá de enfrentar, de início, a questão: Foi Platão, à parte o estudioso de matemática, o entusiasta por essa ciência, também um efetivo matemático? Isto é, descobriu ele resultados matemáticos, resolveu complexos problemas, vislumbrou novas teorias, em suma, imprimiu sua pegada no solo fértil dessa disciplina?

Parece fácil a resposta!

Do seguinte modo, sobre isso, se exprimem dois eminentes historiadores. Allman: 
Deve-se recordar que Platão - que em matemática parece ter sido mais diligente que inventivo (...). De fato, temos somente de comparar a solução atribuída a Platão, para o problema de achar duas médias proporcionais - (...) - com as soluções altamente racionais, para o mesmo problema, de Árquitas e de Ménecmo, para ver o amplo intervalo entre estes e aquele, de um ponto de vista matemático. (...). É, então, provável que Platão, que, tanto quanto o sabemos, nunca resolveu uma questão geométrica (Allman, 1976, p. 124).

Bourbaki:

Pode-se dizer que Platão era quase obsecado pela matemática; sem ser ele mesmo um inventor nesse domínio (Bourbaki, 1969, p. 12).

A próxima questão vem naturalmente: Pode Platão, sem ter sido propriamente um matemático, ter dado uma contribuição importante para o estabelecimento da matemática grega?

Eis aberto um amplo campo de debate.

A tradição, bem como alguns modernos historiadores, consideram decisiva sua colaboração ao desenvolvimento da matemática, mormente no que respeita a método, à sistematização e aos fundamentos da mesma, bem como a sua emancipação da experiência. Outros negam-lhe a influência significativa.

Aos exemplos! Van der Waerden:

O período (século do Platão) começa com a morte de Sócrates (399) e se encerra no momento em que Alexandre, o Grande, espalha a semente da cultura helenística sobre o mundo todo da antiguidade. Esse período é de decadência política; mas para a filosofia e para as ciências exatas é uma era de florescimento sem precedente. No centro da vida científica encontra-se a personalidade de Platão. Ele guiou e inspirou o trabalho científico dentro e fora de sua Academia. Os grandes matemáticos Teeteto e Eudoxo, e todos os outros enumerados no Catálogo de Proclus, foram seus amigos, seus mestres em matemática e seus discípulos em filosofia. Seu grande aluno Aristóteles, o professor de Alexandre, o Grande, passou vinte anos de sua vida no glorioso mundo da Academia (van der Waerden, 1954, p. 148). 
Gow:

Platão foi mais um forjador de matemáticos do que um matemático distinguido por descobertas originais e suas contribuições à geometria estão mais no melhoramento de seu método do que em adições a seu conteúdo. Foi ele que transformou a lógica intuitiva dos antigos geômetras em um método a ser usado conscientemente e sem receio. Com ele, aparentemente, começaram aquelas definições dos termos geométricos, aquele enunciado distinto de postulados e axiomas que Euclides adotou (Gow, 1968, p. 175-6).

Gino Loria:

Mais direta e visível foi a benéfica influência de Platão sobre a ciência exata (Loria, 1929, p. 78).

Mas, também temos Neugebauer:

Parece-me igualmente impossível dar qualquer "explicação" conclusiva para a origem da matemática superior nos séculos $\mathrm{V}$ e IV, em Atenas e nas colônias italianas. Do lado negativo, entretanto, penso que é evidente que o papel de Platão foi amplamente exagerado. Sua contribuição direta ao conhecimento matemático foi obviamente nula. Que, por um curto período, matemáticos da estatura de Eudoxo tenham pertencido a seu círculo não é prova da influência de Platão na pesquisa matemática. $O$ caráter excessivamente elementar dos exemplos de procedimentos matemáticos citados por Platão e por Aristóteles não dão suporte à hipótese de que Teeteto ou Eudoxo tenham aprendido qualquer coisa com Platão (Neugebauer, 1969, p. 152).

Cabe mencionar, agora, a visão de Eudemo, discípulo de Aristóteles, sobre a questão. $\bigcirc$ fragmento da obra de Eudemo que nos interessa foi exposto por Proclus, no famoso Catálogo dos Geômetras:

Platão, que viveu depois desses, deu um impulso a toda a ciência matemática e, em particular, à geometria, pelo apaixonado estudo que este lhe dedicou, e que tornou conhecida, seja enchendo seus escritos de argumentos matemáticos, seja despertando em toda parte 
a admiração por esse estudo naqueles que se dedicam à filosofia. Nesse tempo, também viveram Leodamas de Tasos, Árquitas de Tarento e Teeteto de Atenas, que aumentaram o número de teoremas e deram a eles uma ordenação mais científica. Depois, seguem Neóclides, mais novo do que Leodamas, e seu discípulo Léon, que adicionaram muitas coisas novas àquelas de seus predecessores, tanto que Léon compôs também Elementos muito mais acurados pelo número e pelo valor das demonstrações, (...). Mas Eudoxo de Cnido, um pouco mais jovem do que Léon, e que foi companheiro de discípulos de Platão, foi o primeiro a aumentar o número dos chamados teoremas gerais e juntou outras três proporções às três já conhecidas; além disso, aumentou o número de proposições sobre a seção iniciada por Platão, servindo-se para isso do método de análise ( $\tau \alpha \hat{\imath} \varsigma$

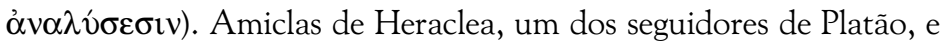
Ménecmo, um estudante de Eudoxo, mais também freqüentador de Platão, e seu irmão Dinóstrato aperfeiçoaram ainda mais a geometria em seu todo. Téudio de Magnésia aparece como excepcional não só em matemática, mas também em todas as partes da filosofia; e de fato, compôs Elementos de um modo excelente e tornou mais gerais muitas proposições particulares. E ainda Aténeu de Cízico, vivendo na mesma época, tornou-se célebre em toda a ciência matemática, mas especialmente em geometria. E Eudemo arremata: "Esses viviam todos juntos na Academia e fizeram suas pesquisas em comum" (Proclus, 1873, p. 66-7).

Como Eudemo é uma das testemunhas mais próximas de Platão que conhecemos, devemos-lhe, sem dúvida, crédito. Talvez seja ele o inspirador de Cajori, quando este escreve:

Com Platão como chefe da Escola, não nos devemos surpreender que a escola platônica tenha produzido um tão grande número de matemáticos. Platão realizou pouco trabalho realmente original, mas fez aperfeiçoamentos valiosos na lógica e nos métodos empregados (Cajori, 1985, p. 26).

Assim, aceitaremos que, mesmo não sendo efetivamente um matemático, Platão contribuiu para o desenvolvimento da matemática grega, em especial da geometria, como ela aparece em uma das obras maiores da antiguidade, os Elementos de Euclides. 


\section{Como se organiza a matemática}

Comecemos por descrever, concisamente, em que consiste, hoje em dia, uma teoria matemática.

Ao desenvolver uma teoria, a missão do matemático é definir os conceitos da teoria e demonstrar as propriedades de tais conceitos. Ora, definir um conceito significa explicá-lo em termos de outros conceitos já definidos, e demonstrar uma proposição significa argumentar sobre sua validade, usando as regras de inferência fornecidas pela lógica, a partir de proposições já anteriormente demonstradas. Então, um certo conceito c é definido em termos dos conceitos, $\mathrm{c}_{1}$, $\mathrm{c}_{2}, \ldots, \mathrm{c}_{\mathrm{k}}$, todos eles definidos anteriormente; cada um desses foi definido em termos de outros conceitos, e "assim por diante". Por exemplo, na teoria matemática dos grupos, o conceito de "grupo" é definido como "um monóide em que todo elemento é invertível", ou seja, a noção de "grupo" é explicada em termos das noções de "monóide" e de "elemento invertível". Por sua vez, um "monóide" é definido como "um semigrupo com elemento identidade"; um "semigrupo", como um "conjunto (não vazio) com uma lei de composição associativa", e "assim por diante". De modo similar, para provarmos uma proposição $\mathrm{p}_{\mathrm{o}}$, usamos proprosições, $\mathrm{p}_{1}, \mathrm{p}_{2}, \ldots, \mathrm{p}_{\mathrm{n}}$, já demonstradas. E, na demonstração de cada uma dessas proposições, aparecem outras, anteriormente demonstradas, e "assim por diante".

Quer na definição de conceitos, quer na demonstração de proposições, o problema se aloja na frase "assim por diante". Por não termos a possibilidade de um retrocesso ad infinitum, devemos oferecer uma solução exeqüível ao "assim por diante".

Há a solução dos dicionários, para o caso da definição de conceitos, ou a solução do "círculo vicioso", em que um conceito é definido em termos de um outro e esse outro, em termos do primeiro; e há a solução do matemático, que consiste em aceitar alguns conceitos sem definição, com o compromisso de, a partir desses, definir todos os demais conceitos da teoria em questão. No caso da demonstração de proposições, por um procedimento análogo, o matemático aceita algumas proposições sem demonstração, com o acordo de, a partir dessas, demonstrar todas as outras. Como diz Duhamel:

É por entendê-lo desse modo que diremos que a definição de uma coisa é a expressão de suas relações com coisas conhecidas. E, por conseqüência, nem todas as coisas podem ser definidas, pois que, 
para isso, seria necessário conhecer já as outras (Duhamel, 1885, p. 16-7).

Os conceitos não definidos são chamados conceitos primitivos, e todos os outros, conceitos derivados. As proposições aceitas sem demonstração são ditas axiomas, e as demonstradas, teoremas. Assim, resumidamente, uma teoria matemática é constituída de conceitos primitivos e derivados, de axiomas e teoremas.

Essa estruturação da matemática é, essencialmente, uma herança grega. Conforme afirma Bourbaki, a "noção de demonstração, nesses autores (sc. Euclides, Arquimedes, Apolônio), não difere em nada da nossa" (Bourbaki, 1969, p. 10).

\section{A matemática grega}

Um dos mais importantes capítulos da história da matemática, embora bem pouco conhecido, é a transformação do primitivo conhecimento matemático empírico dos egípcios e babilônios na ciência matemática grega, dedutiva sistemática, baseada em definições e axiomas.

Quem se achegue descuidadamente a essa história, terá a impressão de a matemática (geometria) ter nascido adulta da cabeça de Euclides, como Atenas triunfante da cabeça de Zeus. Tal foi o sucesso de seus Elementos no resumir, corrigir, dar base sólida e ampliar os resultados até então conhecidos - Proclus diz-nos que Euclides "coletou os Elementos, ordenou no sistema muitas coisas de Eudoxo, aperfeiçoou muitas de Teeteto, e transformou em demonstrações irrefutáveis aquelas que seus predecessores tinham demonstrado pouco rigorosamente" (Proclus, 1873, p. 68) - que Euclides apagou, quase que completamente, os rastros dos que o precederam.

Bourbaki salienta que "não há, hoje, qualquer dúvida de que houve uma matemática pré-helênica bem desenvolvida. Não somente são as noções (já muito abstratas) de número inteiro e de medida de quantidade comumente usadas nos documentos mais antigos que nos chegaram do Egito ou da Caldéia, mas a álgebra babilônia, por causa da elegância e segurança de seus métodos, não deve ser concebida como uma simples coleção de problemas resolvidos por um tatear empírico" (Bourbaki, 1969, p. 9). No entanto, não encontramos, seja nos documentos egípcios, seja naqueles da já mais encorpada matemática babilônia, qual- 
quer traço do que se assemelhe a uma "demonstração", no sentido formal da palavra. O conceito de ciência dedutiva era desconhecido dos povos orientais da antiguidade. Seus textos matemáticos, que chegaram até nós, são, em geral, coletâneas de problemas, mais ou menos interessantes, e suas soluções, em forma de prescrição, como as indicações das etapas de um ritual, oferecido a uma deidade. Nada de teoremas e demonstrações, nada de definições, nada de axiomas.

Agora, a questão fundamental!

Ao herdarem esse conhecimento matemático - pois Heródoto, Aristóteles e Eudemo são unânimes em garantirem ter a geometria vindo do Egito, e no Catálogo dos Geômetras lê-se: "Tales, que viajou ao Egito, foi o primeiro a introduzir essa ciência na Grécia” -, por que os gregos não se contentaram com seu fundamento empírico? Por que substituiram a coleção existente das receitas matemáticas por uma ciência dedutiva sistemática? $\mathrm{O}$ que os levou a confiar mais no que podiam demonstrar do que no que podiam "ver" como correto? Por que a mudança no critério de verdade em matemática, da justificação pela experiência àquela por razões teóricas?

É nessa nova configuração da matemática, julgamos, que a influência de Platão foi decisiva.

\section{A mudança}

No Egito e na Mesopotâmia, era a classe sacerdotal a detentora do conhecimento, em geral, e do conhecimento matemático, em particular. Ora, os sacerdotes eram os intermediários entre a divindade e o povo. Os desígnios da divindade não carecem de explicações; seus desejos devem ser satisfeitos e os rituais e as oferendas aplacam-lhe a ira, atraem seu beneplácito. Aos sacerdotes cabiam interpretar a vontade dos deuses e guiar o povo nas etapas do rito apaziguador.

Seguem esse mesmo estilo seus documentos matemáticos!

Quando esse tipo de conhecimento chega à Grécia, por volta do século VI a.C., não havia lá uma classe sacerdotal, pois, segundo Burnet, "foi provavelmente devido aos aqueus que os gregos nunca tiveram uma classe sacerdotal, e isso pode bem ter tido algo a ver com o aparecimento da ciência livre entre eles" (Burnet, 1957, p. 4). Além disso, "a visão tradicional do mundo e as costumeiras regras de vida tinham colapsado” (id., ib., p. 1) e os mais antigos filósofos especu- 
lavam sobre o mundo a sua volta. Essa pesquisa cosmológica deu origem “ à ampla divergência entre ciência e senso comum, que era, por si mesma, um problema que demandava solução, e, além disso, forçava os filósofos ao estudo dos meios de defender seus paradoxos contra os preconceitos da (visão) não científica" (id., ib., 1957, p. 1). Então, há que se acrescentar, com Bourbaki, "a impressão geral que parece resultar dos textos (muito fragmentários), que possuímos sobre o pensamento filosófico grego do $\mathrm{V}$ século a.C., é que ele é dominado por um esforço mais e mais consciente para estender a todo o campo do pensamento os procedimentos de articulação do discurso empregado com tanto sucesso pela retórica e pela matemática contemporâneas - em outras palavras, para criar a Lógica, no sentido mais geral dessa palavra. $\mathrm{O}$ tom dos escritos filosóficos sofrem, nessa época, uma mudança básica: enquanto que, nos séculos VII e VI, os filósofos afirmam ou vaticinam (ou, ao menos, esboçam vagos raciocínios, fundados sobre igualmente vagas analogias), a partir de Parmênides e, sobretudo, de Zenão, eles argumentam e procuram resgatar princípios gerais que possam

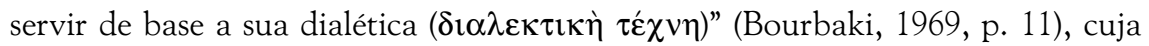
invenção Aristóteles atribui a Zenão; "é em Parmênides que se encontra a primeira afirmação do princípio do terceiro excluído, e as demonstrações por absurdo de Zenão de Elea permaneceram famosas" (Bourbaki, 1969, p. 11).

Pois bem, a solução proposta ao problema da origem da matemática dedutiva sistemática grega é ela ter-se dado pelo impacto, na matemática, da filosofia eleática, ou, mais precisamente, de sua dialética.

Convém notar que tal filosofia foi preparada por Xenófanes, estabecida por Parmênides e seguida e defendida por Zenão e Melisso. Os fundamentos dessa doutrina são, em primeiro lugar, a unidade, a imutabilidade e a necessidade do ser (Platão, Teeteto 181 a 6, fala dos eleatas como os "partidários do Todo", toà Ólou stasiîtai, e Aristóteles, Metafísica 986b24, diz-nos que Xenófanes "referindo-se ao mundo todo, diz que Um era deus"). Em segundo lugar, temos a acessibilidade do ser só ao pensamento racional e a condenação do mundo sensível e do conhecimento sensível como aparência. Essa segunda característica é responsável, cremos, pela mudança da matemática empírica para a matemática teórica.

Neste ponto, é preciso lembrar uma passagem do Fédon, 99d-100a:

Bem, depois disso, disse Sócrates, quando eu estava esgotado com minhas investigações físicas, ocorreu-me que deveria guardar-me 
do mesmo tipo de risco que correm as pessoas, quando vêem e estudam um eclipse do sol; elas realmente prejudicam seus olhos, algumas vezes, a menos que estudem seu reflexo na água ou em algum outro meio. (...). Assim, decidi recorrer a teorias e a usá-las na tentativa de descobrir a verdade sobre as coisas. (...). Em todo caso, primeiro estabeleço a teoria que julgo ser a mais correta e, então, o que parece concordar com ela - em relação a causas ou a qualquer outra coisa - assumo ser verdadeiro, e o que não, assumo não ser verdadeiro.

\section{A conjectura de Szabó}

Vamos, agora, à argumentação de Szabó (Szabó, 1967) em favor da influência da dialética eleática na matemática grega; mais corretamente, em como esta aparece estruturada na grande obra de Euclides.

Euclides abre os Elementos arrolando três tipos de princípios matemáticos:

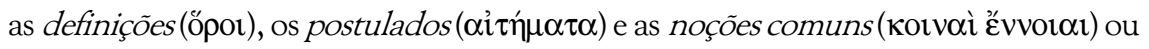
axiomas.

Apenas para servir de ilustração.

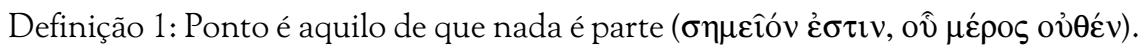

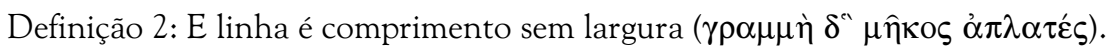

Definição 3: E as extremidades de uma linha são pontos ( $\gamma \rho \alpha \mu \mu \hat{\eta} \varsigma \delta^{\prime \prime} \pi \varepsilon ́ \rho \alpha \tau \alpha$ $\sigma \eta \mu \varepsilon \hat{\imath} \alpha)$.

Postulado 1: Fique postulado conduzir a partir de todo ponto até todo ponto

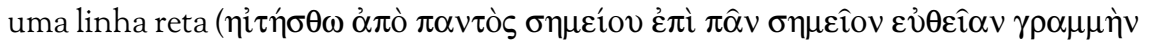

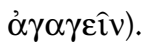

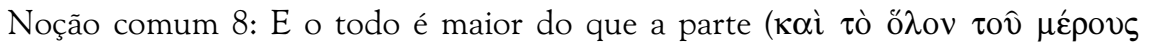
$\mu \varepsilon \hat{\imath}(\mathrm{ov})$.

No século V d.C., Proclus, o escoliasta neo-platônico dos Elementos, examina os princípios não provados da matemática, nos seguintes termos: 
Como essa ciência da geometria é baseada, como dissemos, em hipóteses e demonstra suas proposições posteriores a partir de determinados primeiros princípios - porque há somente uma ciência não hipotética, as outras ciências recebendo dela seus primeiros princípios - é necessário que o ordenador dos elementos na geometria apresente separadamente os princípios da ciência e as conclusões que seguem dos princípios, dando razões, não para os princípios, mas somente para suas conseqüências. Pois nenhuma ciência demonstra seus próprios princípios ou apresenta razões para eles: antes, cada uma tem-nos como auto-evidentes, isto é, como mais evidentes do que suas conseqüências. E a ciência conhece os princípios por si mesmos e as conseqüências por meio daqueles (Proclus, 1873, p. 76).

Ao escrever isso, parece que Proclus faz eco à seguinte passagem de Platão, República 510 c-d:

Sabes [diz Sócrates], imagino, que os que se aplicam à geometria, à aritmética ou às ciências que tais supõem o par e o ímpar, as figuras, as três espécies de ângulo e outras coisas análogas (’’ $\delta \varepsilon \lambda \varphi \alpha ́)$, para cada pesquisa diferente; que, tendo admitido essas coisas como se as conhecessem, não se dignam dar as razões delas a si próprios ou a outrem, julgando que são claras a todos; que, enfim, partindo daí, deduzem o que se segue e acabam atingindo, de maneira conseqüente, o objeto a que sua indagação visava.

Essa passagem mostra que os matemáticos daquela época, dos quais os maiores representantes estavam, de algum modo, associados a Platão, vivendo "todos juntos na Academia" e fazendo "suas pesquisas em comum", tinham já uma nova concepção da matemática como ciência dedutiva e entendiam a não necessidade de demonstrarem seus princípios. Deixa claro, também, que os conceitos arrolados - o par, o ímpar, as figuras geométricas, os três tipos de ângulo são as chamadas hipóteses da matemática e que a matemática, por conter hipóteses, é uma ciência hipotética.

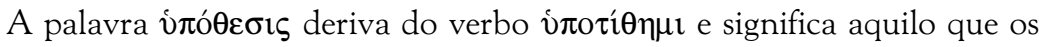
dois participantes de um debate concordam em aceitar como base e ponto de partida de seu debate (como aparece na seguinte passagem de Xenofontes, Mem.

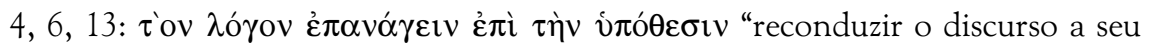

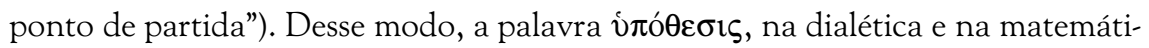


ca, é um ponto de partida, impossível de demonstrar; e não necessita de demonstração, porque os participantes do debate aceitam-na de comum acordo. Então, segundo Szabó, os matemáticos chegaram à conclusão de que os princípios de sua ciência não podiam ser provados, e não necessitavam de demonstração, pela prática da dialética. Estavam habituados com o fato de que, quando um dos debatedores queria provar algo para o outro, estava limitado a começar a partir de uma afirmação aceita por ambos.

\section{A tese}

A mudança, pois, da matemática "empírica" para a matemática "pura" está intimamente associada ao caráter idealista, anti-empírico da filosofia eleática e, sobretudo, da filosofia de Platão. Como nota van der Waerden a respeito do platonismo:

Verdade, que significa as idéias. São as idéias que têm Ser verdadeiro, não as coisas que são observadas pelos sentidos. As idéias podem, às vezes, ser contempladas, em momentos de Graça, através da reminiscência do tempo em que a alma vivia mais perto de Deus, no reino da Verdade; mas isso pode acontecer somente depois de os erros dos sentidos terem sido conquistados pelo pensamento concentrado. O caminho que leva a esse estado é aquele da dialética (van der Waerden, 1954, p. 148).

Platão incentiva a estruturação dedutiva sistemática da ciência matemática, porque a considera propedeútica à dialética, pois

separando-se, ao mesmo tempo, dos pitagóricos, que mantinham no mesmo plano ciência e filosofia, e de Sócrates, cuja investigação prudente parece ter-se detido na determinação da hipótese, Platão conduz a filosofia matemática a um caminho todo novo. A matemática situada na região da $\delta$ ióvol $\alpha$ é apenas uma ciência interme-

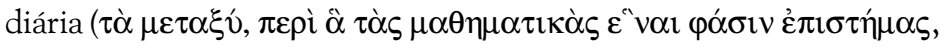
Aristóteles, Met. B2, 997 b 2). Sua verdade reside em uma ciência superior, que está em relação a ela como ela mesma em relação à percepção do concreto. A dialética tem por função retomar as hipóteses das técnicas particulares e de conduzi-las até seu princípio 


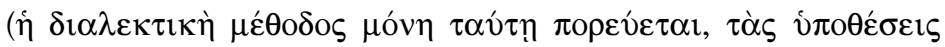

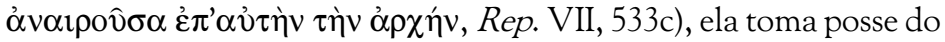
incodicional; e de lá, por uma marcha que é inversa à da análise, forja uma cadeia ininterrupta de idéias (Rep. VI, 511b) que suspensa no princípio absoluto, constituirá um mundo completamente independente do sensível, o mundo da vónors. A filosofia matemática de Platão, em seu grau mais alto e sob sua forma definitiva será, então, a dialética (Brunschvicg, 1985, p. 56).

Será interessante cotejarmos a passagem que acabamos de citar com as seguintes considerações de Bertrand Russell:

A matemática é um estudo que, quando começamos a partir de suas porções mais familiares, pode ser perseguido em uma de duas direções opostas. A direção mais familiar é construtiva, para complexidade gradualmente crescente: dos inteiros para frações, números reais, números complexos; da adição e multiplicação para a diferenciação e a integração e para a matemática superior. A outra direção, que é menos familiar, procede, por análise, à abstração e à simplicidade lógica cada vez maiores; em vez de perguntar o que pode ser definido e deduzido do que é assumido no princípio, perguntamos que idéias e princípios mais gerais podem ser encontrados, em termos de que nosso ponto de partida possa ser definido ou deduzido. É o fato de perseguir essa direção oposta que caracteriza a filosofia matemática como oposta à matemática ordinária (Russell, 1919, p. 1).

Enquanto Zenão toma uma hipótese como uma suposição que se faz para um presente propósito, Platão, no Fédon e nos livros VI e VII da República,

tenta tornar suas suposições aquelas que não têm de ser tomadas como certas para o presente caso particular; ele tenta torná-las aquelas que devem ser aceitas por todos. Essa é a procura da

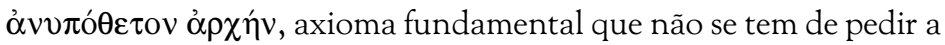
alguém aceitá-lo; é algo que deve ser aceito por qualquer um, (...). É por essa razão que Platão sugere à consideração o ideal axiomático: que deveríamos tentar e desenvolver o todo de nossa matemática por raciocínio dedutivo, $\delta$ ióvor $\alpha$, a partir de alguns princípios, que ele (erradamente) pensou que poderiam ser estabelecidos além de 
toda questão possível. Platão apresentou seu programa. Seus discípulos, em grande parte, realizaram-no. Temos o resultado final, codificado por Euclides (Lucas, 1967, p. 13).

Afinal, de acordo com Plutarco (Quaest. Conv. VIII, 2):

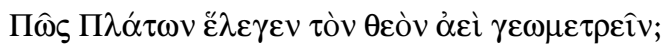

\section{Nota}

* Professor Titular do Departamento de Matemática do Instituto de Geociências e Ciências Exatas da UNESP de Rio Claro.

\section{ReferênCias Bibliográficas}

ALLMAN, G. J. Greek Geometry: from Thales to Euclid. New York: Arno Press, 1976.

BOURBAKI, N. Éléments d'histoire des mathématiques. Paris: Hermann, 1969.

BRUNSCHVICG, L. Les Étapes de la Philosophie Mathématiques. Paris: A. Blanchard, 1985.

BURNET, J. Early Greek Philosophy. New York: Meridian Books, 1957.

CAJORI, F. A History of Mathematics. 4 ed. New York: Chelsea, 1985.

DUHAMEL, J.-M. C. Les Méthodes dans les Sciences de Raisonnement. 3 ed. Paris: Gauthier-Villars, 1885.

GOW, J. A Short History of Greek Mathematics. New York: Chelsea, 1968.

LORIA, G. Storia delle Matematiche. Milano: Ulrico Hoepli, 1929. 3 v.

LUCAS, J. R. Plato and the axiomatic method. In: LAKATOS, I. (ed.). Problems in the Philosophy of Mathematics. Amsterdam: North-Holland, 1967. p. 11-4.

NEUGEBAUER, O. The Exact Sciences in Antiquity. 2 ed. New York: Dover, 1969.

PROCLUS. In primum Euclidis Elementorum Librum commentarii. Recognouit G. Friedlein. Leipsig: Teubner, 1873. 
RUSSELL, B. Introduction to Mathematical Philosophy. London: George Allen \& Unwin, 1919.

SZABÓ, A. Greek Dialectic and Euclid's Axiomatics. In: LAKATOS, I. (ed.). Problems in the Philosophy of Mathematics. Amsterdam: North-Holland, 1967. p. 1-8.

VAN DER WAERDEN, B. L. Science Awakening. Groningen: P. Noordhoff, 1954.

BICUDO, Irineu. Plato and the mathematics.

ABSTRACT: Dialectic, as invented by Zeno, was a rhetorical technique. It consisted of accepting, in the beginning of a discussion, certain hypothesis, without caring about they being true or not. The mathematicians were led to the idea of organizing deductively their science inspired on that technique. But such an organization, as a project, was influenced by Plato's dialectic.

KEYWORDS: deductive method; dialectic; mathematics. 